\title{
Methods Of Teaching To The Course Of Accounting Information Systems: Factors Of Preference
}

\author{
Yousef Shahwan, (Email: yshahwan@uaeu.ac.ae), United Arab Emirates University, United Arab Emirates
}

\begin{abstract}
Accounting information systems (AIS) is a new course of accounting in the sense that the methods of teaching may differ from one school to another. There has been no such of a standard outline that best describes the important topics to be covered in the course of AIS (McCarthy 1999). Although much effort has been made towards the development of standard lists of topical materials, the space is widely open for research in this debate. It has been noted recently that AIS course textbooks include the relational database design and development as an important part adopted by instructors in teaching the course of AIS (Hollander et al. 2006; Romney and Steinbart 2006). This paper evaluates the current situation for teaching methods sued in the course of AIS and indicates several factors that may preference one method over another method of teaching to the AIS course. It reviews a variety of methods adopted in teaching AIS with emphasize on the data modeling approach using cardinalities and the documentation techniques of flowcharting. The study indicates that preference among variety of teaching methods is based on the method that may increase students' motivation and desire to study AIS, and the relevancy and reliability of the business system. It also indicates that improving students' ability to cope with the higher volatility of systems' requirements now days is another factor that may preference one over another methods of teaching to the course of the AIS.
\end{abstract}

Key Words: Accounting Information Systems (AIS), System's Relevancy and Reliability, Students Motivation, Flowcharting, Data Modeling, Resources-Events-Agents (REA), Cardinalities.

\section{INTRODUCTION}

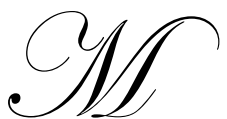

uch work has been done in the case of data modeling approach to be included as a standard topic in the course of accounting information systems, but there has yet to appear an implementation using REA data modeling in a computer accounting systems. The REA data modeling approach is considered in teaching AIS in which an arbitrary is always noticed. The American Accounting Association (AAA) started to address considering information technology in the curricula of accounting programs since late 1950. Several committees have been created to consider the inclusion of computer data processing into accounting curriculum and some of which were in 1959 Committee on Accounting Instruction in Electronic Data Processing; in 1963 Committee on Accounting Systems Instructions; in 1964 Committee on Electronic Data Processing; in 1969 Committee on the Role of the Computer in Accounting Education; and in 1970\&71 Committee on Information Systems. All these committees have given the subject massive amount of time and made significant effort towards the need of including IT in accounting programs. They, in particular the Committee on Information Systems, indicated that a developed consensus on recognizing the accounting information systems course (AIS) as essential to the undergraduate accounting program.

In recent years, the curriculum of the accounting programs has been the subject of great controversy in US as well as internationally. The central issue surrounding the accounting program curriculum is basically derived 
from the absence of IT, among various teaching methods, in the undergraduate accounting program. Such programs vary substantially across business schools. In specific, an issue of focus is whether IT techniques are considered in the curriculum of undergraduate programs. This paper evaluates the current situation for teaching methods used in the course of AIS and indicates several factors that may preference one method over another method of teaching to the AIS course. It reviews a variety of methods adopted in teaching AIS with emphasize on the data modeling approach using cardinalities and the documentation techniques of flowcharting. Two research questions are addressed. The first research question is whether students' satisfaction and desire to study the course of AIS and the relevancy and reliability of the business software system are increased by the method(s) adopted. The second research question is whether the students' ability to cope with current volatility systems' requirements are improved by the method(s) adopted.

\section{ACCOUNTING STUDIES AND DATABASE GOLDEN AGE}

IT has faced rapid changes in sharing the interpretation and developments and various aspects of different fields such as the accounting field. The years of late 1960s and early 1970s were the middle of database golden age. Codd (1970) was initiated the relational model of data as a basis for protecting users of formatted caused by growth in the data bank and changes in traffic. It was the introduction of a normal form for the time-varying collection of relationships. Also, he discussed certain operations and relations (other than logical inferences) and applied two types of redundancy to the problem of maintaining the data a consistent as more and more different types of data are integrated together into common data banks.

Chen (1976) proposed the data model called entity-relationship model. This model incorporates some of the important semantic information about the real world. A special diagramming technique is introduced as a tool for database design. An example of database design and description using the model and the diagramming technique is given. Some implications for data integrity, information retrieval, and data manipulation are discussed. The entityrelationship model can be used as a basis for unification of different views of data: the network model, the relational model, and the entity set model. Semantic ambiguities in these models are analyzed. Possible ways to derive their views of data from the entity-relationship model are presented.

Smith and Smith (1977) defined two kinds of abstraction that are fundamentally important in database design and usage. Aggregation is an abstract which turns a relationship between objects into an aggregate object. Generalization is an abstraction which turns a class of objects into a generic object. It is suggested that all objects (individual. Aggregate, generic) should be given uniform treatment in models of the real world. A new data type, called generic, is developed as a primitive for defining such models. Models defined with this primitive are structured as a set of aggregation hierarchies intersecting with a set of generalization hierarchies. Abstract objects occur at the points of intersection. This high level structure provides a discipline for the organization of relational database. In particular, this discipline allows: (i) an important class of views to be integrated and maintained; (ii) easier understanding of complex models and more natural query formulation; (iv) a more systematic approach to database design; (v) more optimization to be performed at lower implementation levels. The generic type is formalized by a set of invariant properties. These properties should be satisfied by all relations in a database if abstractions are to be preserved. A triggering mechanism for automatically maintaining these invariants during update operations is proposed. A simple mapping of aggregation hierarchies onto owner-coupled set structure is given.

Wu (1983) argued that the course of AIS is new in the sense that no standard methods exist in teaching AIS. As such, universities and schools may vary substantially in the way of teaching the course of AIS. Wu (1983) evaluated the state of the art of teaching AIS and proposed a generalized model for teaching the AIS course. He used questionnaire surveys to find which topics should include and not to include in the AIS course so that a standard topic of outline can be developed and recommended in teaching the AIS course. The questionnaire surveys were completed by specialists who are listed as either systems, EDP (electronic data processing), or MIS (management information systems) in Prentice-Hall's Accounting Faculty Directory (1980). 
Table 1 presented AIS instructors' perception of important topics that should be covered in the course of AIS. As noted in Table 1 that topics of importance that should be included in the AIS course are:

- $\quad$ The conceptual foundations of AIS including IS-based concepts.

- $\quad$ Data processing cycle approach including data input, process, storage and information output.

- $\quad$ Documentation techniques including document and systems flowcharts.

- System life cycle including systems analysis and conceptual design, development and implementation.

- Internal control including computer-based AIS and computer frauds.

- $\quad$ General ledger, budgetary control, and financial planning and budgeting methods.

- $\quad$ AIS for resources and feedback control including invoicing \& accounts receivable, inventory control, payroll, fixed assets accounting systems, and purchasing and accounts payable.

According to $\mathrm{Wu}$ (1983), topics that should not be included are:

- $\quad$ Historical development of data processing technology including unit record equipment.

- $\quad$ Strategic planning systems

- $\quad$ Decision support systems

- Information theory and information evaluation

Table 1: The Perception of AIS Instructors about topical coverage of AIS course

\begin{tabular}{|c|c|c|c|}
\hline Topics & Necessary & Optional & Unnecessary \\
\hline General systems concepts & 27 & 5 & 1 \\
\hline Systems feedback and organizational control & 24 & 8 & 2 \\
\hline Feedback control and AIS & 35 & 4 & 1 \\
\hline Historical perspective of data processing technology & 7 & 16 & 16 \\
\hline Data processing technology (hardware, software, systems flowcharts, etc.) & 28 & 9 & 7 \\
\hline $\begin{array}{l}\text { Business data processing systems (batch, real-time, database, distributed } \\
\text { systems) }\end{array}$ & 36 & 3 & 5 \\
\hline $\begin{array}{l}\text { Systems life cycle and resources management (systems initiation, analysis, } \\
\text { design, implementation, and control; document flowchart and systems } \\
\text { documentation) }\end{array}$ & 17 & 15 & 6 \\
\hline $\begin{array}{l}\text { Study and evaluation of internal control (including methods of auditing } \\
\text { computer-based AISs and computer frauds) }\end{array}$ & 33 & 1 & 2 \\
\hline General ledger and budgetary control systems & 24 & 14 & 5 \\
\hline $\begin{array}{l}\text { AISs for production and feedback control (order-filling, invoicing, and } \\
\text { A/R systems, inventory control systems, and cash disbursement and A?P } \\
\text { systems) }\end{array}$ & 23 & 13 & - \\
\hline $\begin{array}{l}\text { AISs for production control (production planning, scheduling, costing } \\
\text { systems and fixed assets accounting systems) }\end{array}$ & 25 & 14 & 1 \\
\hline Strategic planning systems & 9 & 22 & 11 \\
\hline Financial planning and budgeting models & 14 & 17 & 9 \\
\hline Decision support systems & 9 & 23 & 10 \\
\hline Information (communication) theory and information evaluation & 7 & 22 & 17 \\
\hline
\end{tabular}

(Source: adapted from Wu (1983) "Teaching Accounting Information Systems: A Synthesis", Issues in Accounting Education 1983.)

Wu (1983) concluded that three methods for teaching AIS course can be recommended and these are: class lecture as the main teaching tool; case study as the first supplementary teaching tool; and programming to be as the second supplementary teaching tool. 
Sangster (1992) argued that the introduction of computer instruction packages may result in alternative to existing teaching methods for accounting. He assessed the background needed to the use of such packages and proposed a six-stage cycle to be followed if such background to be incorporated into accounting courses. Sangster (1992) also examined the use of nine modules from one of the package (the PEER Statements of Standard Accounting Practice course) by a second year student class. Data were collected from the class test, the final exam, and from three questionnaires completed before, in the middle, and at the end of the course. He concluded that the modules have limited value as an additional resource but the supplantive use may be a potential alternative to conventional teaching method.

As shown in Table 2, hypothesis 2, that considered the situation when lecture time was added to the PEER module times resulted in a t-value of 9.54 in favor of supporting SSAPs. With respect to hypothesis 14, a one0tailed paired t-test was conducted. The change in mean confidence from 2.78 to 2.54 was significant and as such evidence was provided to reject the null hypothesis.

Table 2: t-test Results for Research Hypotheses

\begin{tabular}{|c|c|c|c|c|c|c|c|c|}
\hline & Hypothesis & $\mathrm{n}$ & mean & median & Std.dev & $\mathbf{t}$ & $\mathbf{p}$ & Accept $\mathbf{H}_{0}$ \\
\hline 1 & Time difference & 34 & 02300 & 0.0250 & 0.1510 & 1.49 & 0.150 & $\sqrt{ }$ \\
\hline 2 & Time difference & 34 & 1.4500 & 1.7050 & 0.8860 & 9.54 & 0.000 & $x$ \\
\hline $3 \mathrm{a}$ & Time dif 4-v-2 & 43 & 0.3550 & 0.0000 & 0.8370 & 2.78 & 0.008 & $x$ \\
\hline $3 \mathrm{~b}$ & Time dif 4-v-17 & 43 & 0.2130 & 0.0000 & 0.5120 & 2.73 & 0.009 & $x$ \\
\hline $3_{\mathrm{c}}$ & Time dif 4-v-18 & 43 & 0.1400 & 0.0000 & 0.4380 & 2.09 & 0.043 & $x$ \\
\hline $44_{a}$ & Time dif 4-v-12 & 18 & 0.5140 & 0.2500 & 0.8330 & 2.62 & 0.018 & $x$ \\
\hline $4_{b}$ & Time dif 4-v-19 & 18 & 0.4580 & 0.1250 & 0.7960 & 2.44 & 0.026 & $x$ \\
\hline 9 & Exam dif suppl-v-suppo & 50 & 0.0030 & 0.0230 & 0.2270 & 0.09 & 0.930 & $\sqrt{ }$ \\
\hline 10 & Exam suppl use-v-none & - & - & - & - & 0.42 & 0.340 & $\sqrt{ }$ \\
\hline 11 & Exam suppl use-v-none & - & - & - & - & 0.96 & 0.170 & $\sqrt{ }$ \\
\hline 14 & Confidence difference & 50 & 0.2400 & 0.0000 & 0.9570 & 2.58 & 0.006 & $x$ \\
\hline 15 & Literacy difference & 50 & 0.5400 & 0.5000 & 0.7340 & 5.20 & 0.000 & $x$ \\
\hline 16 & Comp dif Tax-v-FA2 & 47 & 1.1700 & 1.0000 & 0.9630 & 8.33 & 0.000 & $x$ \\
\hline 17 & Comp dif MA3-v-FA2 & 47 & 0.0430 & 0.0000 & 0.4150 & 0.70 & 0.490 & $\sqrt{ }$ \\
\hline 18 & Exam dif sample-v-all & 50 & 0.4970 & 0.5140 & 0.1390 & 1.46 & 0.150 & $\sqrt{ }$ \\
\hline 19 & $1^{\text {st }}$ year dif sample-v-all & 46 & 0.6700 & 0.6750 & 0.1290 & 0.64 & 0.530 & $\sqrt{ }$ \\
\hline $20_{\mathrm{a}}$ & Exam dif suppo-v-both & 34 & 0.5130 & 0.5290 & 0.1330 & 0.68 & 0.500 & $\sqrt{ }$ \\
\hline $20_{\mathrm{b}}$ & Exam dif none-v-both & 16 & 0.4640 & 0.4710 & 0.1480 & 0.89 & 0.390 & $\sqrt{ }$ \\
\hline $21_{\mathrm{a}}$ & Year 1dif suppo-v-both & 31 & 0.6780 & 0.6800 & 0.1140 & 0.37 & 0.710 & $\sqrt{ }$ \\
\hline $21_{b}$ & Year 1dif none-v-both & 15 & 0.6550 & 0.6600 & 0.1590 & -0.38 & 0.710 & $\sqrt{ }$ \\
\hline
\end{tabular}

(Source: adapted from Sangster (1992) "Computer-based Instruction in Accounting", Accounting Education 1 (1).

Greets and Waddington (2000) conducted a case study about the Belgian Chocolate Company (BCC) that was used in accounting information systems classes with strong emphasize on the Resource-Even-Agent (REA) data modeling approach. They developed the BCC case to provide a case for use in AIS classes with strong focus on REA data modeling approach and to design a case that is flexible to be used by a large number of AIS instructors regardless there style of teaching, learning objectives, or national preferences. In order to achieve the first objective, Greets and Waddington (2000) addressed the economics activities of a chocolate-making company and graphed its revenue business process (accounting cycle) using the REA data modeling approach. For the second objective, they developed a dynamic web-site to deliver the case materials to students.

A part of interest in the case description is part II "Database Implementation". Students are expected to complete BCC database in MS Access constructed format. Table 3 displays the entities and relationships implemented for students to complete BCC database. 
Table 3: Entities and Relationships Lists been Implemented for Students

\begin{tabular}{|c|c|}
\hline Entities & Relationships \\
\hline Employee (Salesperson and Cashier combined) & Order-Product \\
\hline Customer & Sale-Product \\
\hline Order & Order-Employee (Salesperson) \\
\hline Product & Order-Customer \\
\hline Sale & Order-Sale \\
\hline Warehouse & \\
\hline Cash & \\
\hline
\end{tabular}

Greet et al. (2002) introduced a software called "Stevie" that can be used as a data modeling approach to teach accounting information systems. As an important part of data modeling is the specification of cardinalities, Stevie is an internet tool that helps students learn cardinalities. Two categories of users are identified for Stevie who are students and instructors and administrators. Students use the Stevie in solving cardinalities exercise. Instructors' use of Stevie is limited to create exercise definitions, assignments, and students accounts. Another approach that can be used in teaching accounting information systems is the business processes approach. As discussed earlier that the term "accounting cycle" could be replaced by the more generic term "business process", Hollander at el. (2000).

McCarthy (2003) presented the REA data modeling approach in teaching the course of AIS. It was noted that the REA data model core feature uses a semantic representation of the input and output components of a business process. McCarthy (2003) addressed the database computer science in its hybrid field of AIS. According to McCarthy (2003), there are two advanced REA classes in the AIS curriculum at Michigan State University (MSU):

1. Semantic methods of database design (aggregation, generalization, classification, and typtification) and syntactic methods of database design (dependency-driven normalization). So, it is a conceptual modeling skill.

2. An object-oriented analysis and design class that use Java and heavy use of computer laboratory. The design and implementation are given most of the work material that is about $75 \%$ of the required skills.

Gerard (2005) investigates whether organizing individuals' knowledge according to the REA pattern would improve the accuracy in the conceptual modeling. He argues that such knowledge contributes to the accuracy of conceptual models based on the assumptions that individuals acquire domain knowledge from work experience and conceptual modeling notation enables the translation of domain knowledge into a conceptual model. Gerard (2005) uses the REA pattern as knowledge structure for conceptual modeling of AIS and examines its consequences for the accuracy of conceptual modeling in a retail business. Gerard (2005) sample includes 53 undergraduates and 56 graduate students who completed an E-R model designed to measure conceptual modeling performance accuracy. The results indicate that in order to produce effective conceptual modeling performance, the domain-specific knowledge acquired from experience is insufficient, compared to conceptual modeling notation. The importance of REA pattern is to provide an abstract representation of related-business process entities and relationships that exist among them.

\section{REA DATA MODELING AND CARDINALITIES}

According to Ijiri (1975), REA data modeling is seen as a framework that identifies entity-based descriptions of accounting activities, it classifies entities into three major categories: resources, events, and agents. Resources are those objects that have potential utilities and consequently have economic value and under the control of an organization. Events are those value chain transactions that reflect changes in organizational resources. Agents are those parties (internal or external) that have been involved in value chain activities. In a sales revenue cycle, resources that have been affected by such cycle are the cash and inventory. Sales and cash receipts are examples of economic exchanges of event entities as sales activities lead to reduction in inventory quantity and cash receipts activities result in increment in cash. Salesperson, customer, and cashier are example of agents who may participate in sales transactions. 
McCarthy (1979) argued that REA data modeling approach, among other data modeling approaches, provides a teaching competitive advantage in AIS classes because it has been specifically developed for use in designing AIS database. McCarthy (1982) argued further that REA is adapted to conventions for equity accounting. While Amer (1993) document evidence that entity-relationship data modeling approach is found superior over other data modeling methodologies in facilitating the audit review of accounting application.

As stated earlier that Ijiri (1975) identified the major categories of REA data modeling methodology in the form of resources, events, and agents relationship. These categories are referred to as entities. Entities are related to each other by means of numerical relationship referred to cardinalities (multiplicities). Determining cardinalities is not an arbitrary choice rather it reflects information relationships of the organizational business process and practices. Data base design and development require five stages: systems analysis; conceptual design; physical design; implementation and conversion; and operational and maintenance. Information collected for cardinalities is usually obtained during the stage of systems analysis and conceptual design. Batini et al. (1992) notation is used for determining cardinalities. Therefore, the pairs of letters and numbers that appear next to each entity represent the minimum and maximum cardinalities respectively. Entities represent a class or set of objects. For example, sales entity represents all the individual sales transactions that occur during the period and the customer entity represents all of the organization's customers. Each individual sales and customer transaction represents a specific instance of the entity.

To demonstrate the implication of cardinalities, a standard example of sales revenue cycle is addressed below. It is about an example derived from Romney \& Steinbart (2006). It briefly determines cardinalities of relationships and explains the business meaning of cardinalities. Typical types of relationships are first considered. The cardinalities between events and agents are typical in the sense that each event must participate in a relationship with one type of agent, and at most one type of agent; conversely, each agent can participate $\mathrm{n}$ a relationship with many events, but may be related to no event (this is the situation where new customer can be entered to the system without having to be linked to any event). In addition, the cardinalities between resources such as master files (i.e., cash and inventory) and events are typical in the sense that a new record can be entered to a resource entity without being linked to a specific event entity.

Table 1.4 presents a sample for the REA data modeling approach used to describe the sales revenue cycle and is adapted from Romney and Steinbart (2006). Applying the concepts tackled above, the cardinality that appears next to the cash in a Cash-Cash Receipts relationship is $(0, \mathrm{~N})$ because cash is a master file and some cash accounts (e.g., the savings account) may never be used to deposit cash for sales transactions. The cardinality that appears next to the cash receipts a Cash Receipts-Cash relationship is $(1,1)$ because in this particular situation it seems that each check must be deposited to one, and only one check account bearing in mind that this situation may vary from one case to another.

Assuming that the considered sample sells one type of inventory items, the cardinality that appears next to the inventory in an Inventory-Sales relationship is $(0, \mathrm{~N})$ because at an inventory item can be added without having to be related to a sales event and a given inventory item could have been sold for may times. The cardinality that appears next to sales in a Sales-Inventory relationship is $(1, \mathrm{~N})$ because each sales transaction must participate in at least one inventory item, and may participate in many inventory items. The cardinality that appears next to sales in a Sales-Cash Receipts relationship is $(0,1)$ because the sales transaction happens before the cash receipts in time and paid on cash in full and no installments allowed, it applies only to this particular case. The cardinality that appears next to cash receipts in a Cash Receipts-Sales relationship is $(1,1)$ because cash receipts happens after the sales transaction in time and payments are made by individual customers for specific sales transactions. 
Figure 1: REA Data Modeling Sample for Sales Revenue Cycle (Source: Romney \& Steinbart 2006)

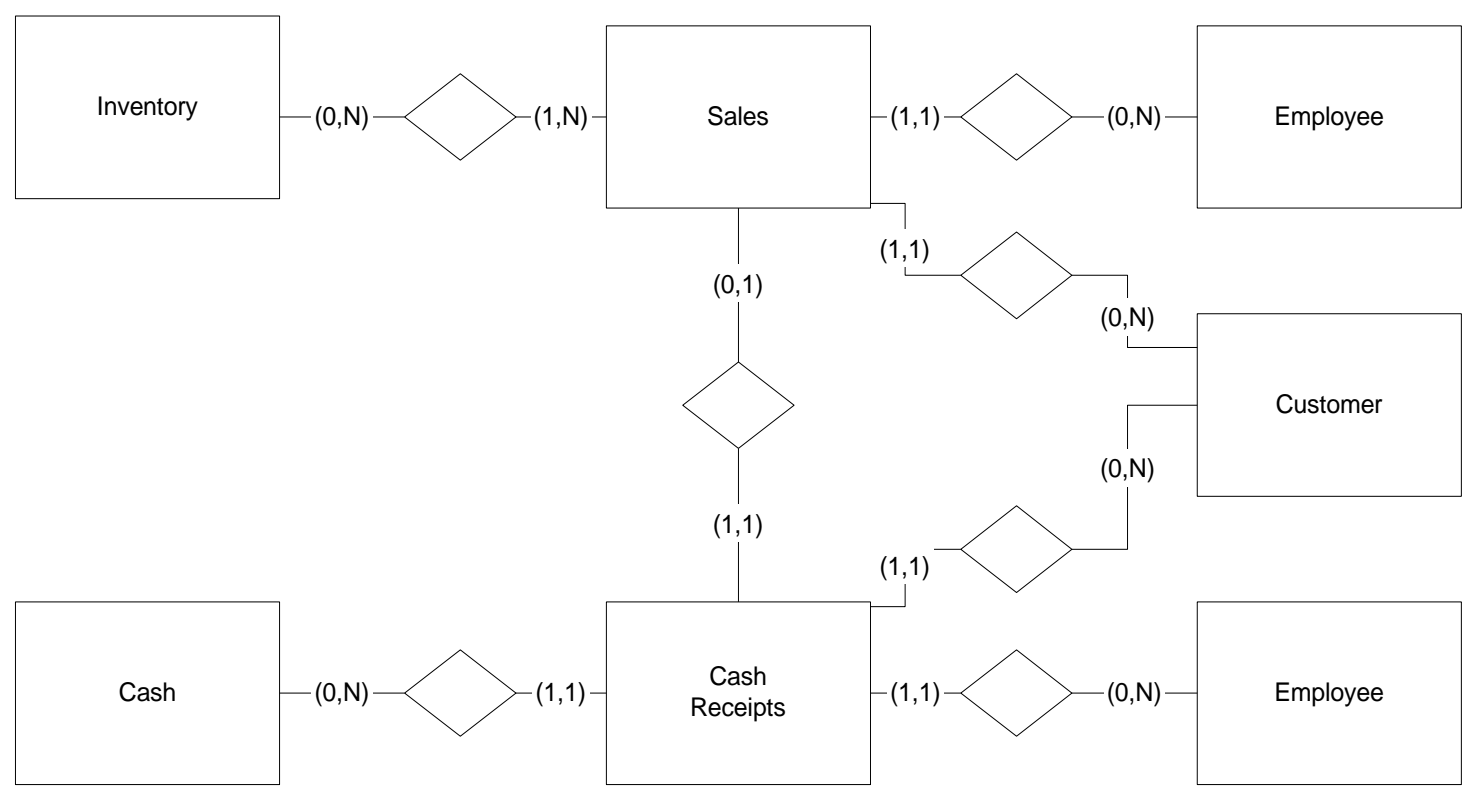

\section{DATA COLLECTION AND SAMPLE}

This study examines the variety of methods adopted in teaching the course of AIS and reveals several factors that may preference one method over another method of teaching to the AIS course. Common teaching methods for the course of AIS, the data modeling approach using cardinalities and the documentation techniques of flowcharting, are reviewed and examined for factors of preference. This paper has two research questions. The first research question is whether students' motivation and desire to study the course of AIS and the relevancy and reliability of the business software system are increased by the method(s) used by instructors. The second research question is whether the students' ability to cope with current volatility systems' requirements is improved by the method(s) used by instructors.

\section{DATA SOURCES}

As mentioned earlier that the major issue of this study is to evaluate the current situation for teaching methods sued in the course of AIS and indicates several factors that may preference one method over another method of teaching to the AIS course. It goes through variety of methods adopted in teaching AIS with particular emphasize on the data modeling approach using cardinalities and the documentation techniques of flowcharting. Thus, the sample should include all those accredited (AACSB) UAE universities which have provided a Bachelor's degree program in accounting with its college of business and economics. To do so, the sample is selected on the basis of the following three criteria: (1) select the UAE universities that are internationally accredited by AACSB as the language of instruction is the English language; (2) exclude universities who do not provide a Bachelor's degree program in accounting; and (3) the course of AIS is a core course required by the program and new materials development has been prepared in the sense that the database systems are included as a topic in the course outline.

The data used for this sample are drawn from students of United Arab Emirates University (UAEU) who studied the course of accounting information systems during the spring semester of the academic year 2006-2007. Students of UAEU were selected due to the following reasons. First, College of Business and Economics (CBE) at UAEU is internationally accredited by AACSB and as such the language of instruction is the English language. Second, CBE provides a Bachelor's Degree program in Accounting. Third, the course of AIS is required as a compulsory course of the program. The academic year 2006-2007 is selected as the relevant time period because of 
that the course of AIS has been newly developed and the inclusion of the database systems approach was incorporated to this new course materials.

\section{Estimation Of REA Data Modeling Approach}

The data modeling approach using cardinalities is estimated by using ordinary least squares (OLS) of Microfit. Table 1.5 presents the regression summary statistics for the preference factors in adopting the teaching method of data modeling approach. The regression coefficients on the volatility of systems requirements and accuracy and wide acceptance variables are positive and statistically significant at p-value of 0.001 and 0.085 respectively. The students' motivation coefficient is positive that is in its predicted direction but statistically insignificant.

Table 1.5: OLS Estimation Results for the REA Data Modeling Approach based on White's Heteroscedasticity Adjusted Standard Errors

\begin{tabular}{|c|c|c|c|c|c|}
\hline $\begin{array}{c}\text { Statistics } \\
\text { / Predicted Sign } \\
\end{array}$ & $\begin{array}{c}\mathbf{X}_{2} \\
+ \\
\end{array}$ & $\begin{array}{c}\mathbf{X}_{3} \\
+ \\
\end{array}$ & $\begin{array}{c}\mathbf{X}_{4} \\
+ \\
\end{array}$ & $\underset{\mathbf{R}^{2}}{\text { Adj. }}$ & $\mathbf{N}$ \\
\hline Beta-value & 0.2354 & 0.2952 & 0.4624 & 0.451 & 57 \\
\hline t-statistic & 1.5638 & 1.7538 & 3.3969 & & \\
\hline p-value & 0.1240 & 0.0850 & 0.0010 & & \\
\hline
\end{tabular}

$\chi_{1}=\alpha_{0}+\alpha_{2} \chi_{2}+\alpha_{3} \chi_{3}+\alpha_{4} \chi_{4}+\varepsilon$

$\chi_{2}=$ Students' Motivation.

$\chi_{3}=$ Accuracy and Wide Acceptance.

$\chi_{4}=$ Volatility of Systems' Requirements.

$\varepsilon=$ Error term.

\section{Discussion Of REA Data Modeling Estimation}

The regression results of the REA Data Modeling approach (Table 1.5) reveal that the coefficients for volatility of systems' requirements and the accuracy and wide acceptance are positive and statistically significant at p-value of 0.001 and 0.085 respectively. So, it can be concluded that students at United Arab Emirates Universities prefer to apply the REA data modeling approach in studying the course of accounting information systems in order to stress the importance of changes in systems' requirements and increase system's relevance and reliability. This is consistent with previous studies in the sense that the adoption of REA Data Modeling approach will improve system's relevance and reliability and meet the challenges in volatility of systems' requirements.

Also, table 1.5 reveals that the coefficient for students' motivation is positive as expected but statistically insignificant. One possible explanation for this result is that the meaning of students' motivation in developing countries' universities is not yet fully absorbed as it usually splits between many factors such as the high marks students obtained, low of assignments and quizzes, and easy of exams contents. Another possible explanation could be the fact that students are not fully aware of the importance of being motivated to study a university course due to the source and origin of their high school qualifications. This is consistent with the survey that appears in Table 3.3 that shows the high school qualifications of the respondents.

\section{Estimation Of Flowchart Documentation Approach}

The flowchart documentation approach is estimated by using ordinary least squares (OLS) of Microfit. Table 1.6 presents the regression summary statistics for the preference factors in adopting the teaching method of flowchart documentation approach. The regression coefficients on students motivation and the volatility of systems requirements variables are positive and statistically significant at p-value of less that 0.05 . The accuracy and wide acceptance coefficient is positive that is in its predicted direction but statistically insignificant. 
Table 1.6: OLS Estimation Results for the Flowchart Documentation Approach based on White's Heteroscedasticity Adjusted Standard Errors

\begin{tabular}{|c|c|c|c|c|c|}
\hline $\begin{array}{c}\text { Statistics } \\
\text { / Predicted Sign } \\
\end{array}$ & $\begin{array}{c}\mathrm{X}_{2} \\
+ \\
\end{array}$ & $\begin{array}{c}X_{3} \\
+ \\
\end{array}$ & $\begin{array}{c}\mathrm{X}_{4} \\
+ \\
\end{array}$ & $\begin{array}{c}\text { Adj. } \\
\mathbf{R}^{2}\end{array}$ & $\mathbf{N}$ \\
\hline Beta-value & 0.7093 & 0.4310 & 0.2622 & 0.497 & 57 \\
\hline t-statistic & 4.4889 & 0.2727 & 2.2023 & & \\
\hline p-value & 0.0000 & 0.7860 & 0.0320 & & \\
\hline
\end{tabular}

$\chi_{1}=\alpha_{0}+\alpha_{2} \chi_{2}+\alpha_{3} \chi_{3}+\alpha_{4} \chi_{4}+\varepsilon$

$\chi_{2}=$ Students' Motivation.

$\chi_{3}=$ Accuracy and Wide Acceptance.

$\chi_{4}=$ Volatility of Systems' Requirements.

$\varepsilon=$ Error term.

\section{Discussion Of Flowchart Documentation Estimation}

The regression results of the flowchart documentation approach (Table 1.6) reveal that the coefficients for students' motivation and the volatility of systems' requirements are positive and statistically significant at p-value of less that 0.05. So, it can be concluded that students at United Arab Emirates Universities prefer to apply the flowchart documentation approach in studying the course of accounting information systems in order to get students more motivated and stress on the importance of changes in systems' requirements now a days.

Table 1.6 also reveals that the coefficient for the accuracy and wide acceptance is positive as expected but statistically insignificant. One possible explanation for this result is that courtiers in developing courtiers run companies that are of similar nature and changes are not usually occurred in the sense that its business processes and accounting activities are maintained at national or at most global levels. Another possible explanation could be the fact that students are not fully aware of the importance of having the accountants contribute to the development of accounting systems database that will ultimately increase systems relevancy and reliability.

\section{CONCLUSION}

This paper investigates whether students may prefer one method over another to teaching the course of accounting information systems (AIS). It empirically examines whether students in United Arab Emirates universities prefer to apply REA data modeling approach and/or flowchart documentation techniques in studying the course of AIS. The empirical test analysis yielded several interesting results. First, the results reveal that students at United Arab Emirates Universities prefer to apply the REA data modeling approach in studying the course of accounting information systems in order to stress the importance of changes in systems' requirements and increase system's relevance and reliability. Second, the results reveal that students at United Arab Emirates Universities prefer to apply the flowchart documentation approach in studying the course of accounting information systems in order to get students more motivated and stress on the importance of changes in systems' requirements now a days.

\section{REFERENCES}

1. Abrial, J. R. (1974). Data Semantics. In Data Base Management, edited by J. W. Klimbie and K. L. Koffeman, 1-60, Amsterdam, The Netherlands: North Holland.

2. Amer, T. S. (1993). Entity-Relationship and Relational Database Modeling Representations for the Audit Review of Accounting Applications: An Experimental Examination of Effectiveness. Journal of Information Systems (Spring): 1-15

3. American Accounting Association (1964). Report of the Committee on Accounting Systems Instruction. Committee on Accounting Systems Instruction. The Accounting Review (July): 715-720.

4. Batini, C., Ceri, S., and S. B. Navathe (1992). Conceptual Database Design. An Entity-Relationship Approach. Redwood City, CA: Benjamin/Cummings Publishing Company Inc.

5. Byers, C. R. \& L. Beltz (1994). Financial Data Modeling at Hewlett Packard. Journal of Systems Management (January): 28-33. 
6. Chen, P. P. (1976). The entity relationship model-Toward a unified view of data. ACM Transactions on Database Systems (March): 9-36.

7. Codd, E. F. (1970). A relational model of data for large shared data banks. Communications of the ACM (June): 377-387.

8. Codd, E. F. (1972b). Relational completeness of data base sublanguages. In Data Base Systems, edited by R. Rustin, 65-98. Englewood Cliffs, NJ: Prentice Hall.

9. Dunn, C. L., and W. E. McCarthy (1997). The REA accounting model: Intellectual heritage and prospects for progress. Journal of Information Systems (Spring): 31-51.

10. Geerts, L. G., and W. E. McCarthy (2001). Using object templates from the REA accounting model to engineer business processes and tasks. Review of Business Information Systems (Fall): 89-108.

11. Geerts, L. G., and Waddington A. B. (2000). The Belgian Chocolate Company: A Dynamic Data Modeling and Database Design Case for the AIS Class Journal of Information Systems, Vol. 14, No. 1, Spring 2000, pp53-74.

12. Gerard, G. J. (2005). The REA Pattern, Knowledge Structures, and Conceptual Modeling Performance. Journal of Information Systems (Fall): 57-77.

13. Hollander, A. S., E. L Denne, and J. O. Cherrington (2006). Accounting Information Technology and Business Solution. $3^{\text {rd }}$ Edition, Burr Ridge, IL:Irwin/McGraw-Hill.

14. Ijiri, Y. (1975). Theory of Accounting Measurement (American Accounting Association, 1975)

15. McCarthy, W. E. (1979). An Entity-Relationship View of Accounting Models. The Accounting Review (October): 667-686.

16. McCarthy, W. E. (1982). The REA Accounting Model: A Generalized Framework for Accounting Systems in a Shared Data Environment. The Accounting Review (July): 554-578.

17. McCarthy, W. E. (2003). The REA Modeling Approach to Teaching Accounting Information Systems. Issues in Accounting Education (November): 427-441.

18. Romney, M. B., and P. J. Steinbart (2006). Accounting Information Systems. $10^{\text {th }}$ Edition. Upper Saddle, NJ: Prentice Hall.

19. Sangster A. (1992). Computer-based instruction in accounting education. Accounting Education 1(1), pp1332.

20. Smith, J. M., and D. C. P. Smith (1977). Database Abstractions: Aggregation and generalization. ACM Transactions on Database Systems (June): 105-133.

21. Wu, H. F. (1983). Teaching Accounting Information Systems: A Synthesis. Issues in Accounting Education, 1983, Issue 1, pp132-146. 